\title{
Faktor-Faktor yang Mempengaruhi Kepatuhan Pengobatan pada Pasien Diabetes Mellitus Rawat Jalan di RSUD Sukoharjo
}

\section{Factors Affecting Medication Adharence in Outpatient Diabetes Mellitus at RSUD Sukoharjo}

\author{
Tri Yulianti*, Lusi Anggraini \\ Fakultas Farmasi Universitas Muhammadiyah Surakarta, Jl. A Yani Tromol Pos 1, Pabelan, Surakarta, \\ Indonesia \\ *E-mail: tri.yulianti@ums.ac.id
}

Received: 7 Oktober 2020; Accepted: 11 November 2020; Published: 31 Desember 2020

\begin{abstract}
Abstrak
Diabetes melitus merupakan penyakit metabolik kronis dengan prevalensi yang selalu meningkat dan apabila tidak ditangani dengan baik akan meningkatkan risiko terjadinya komplikasi. Kepatuhan penggunaan obat merupakan salah satu faktor penentu dalam keberhasilan terapi diabetes mellitus. Tujuan penelitian ini untuk mengetahui faktor-faktor yang dapat mempengaruhi kepatuhan pada pasien diabetes melitus tipe 2 rawat jalan di RSUD Sukoharjo tahun 2020. Penelitian ini merupakan jenis penelitian cross sectional, teknik pengambilan sampel secara purposive sampling. Sebanyak 85 pasien diabetes mellitus type 2 rawat jalan di RSUD Sukoharjo dengan kriteria inklusi mendapatkan terapi OHO (Obat Hipoglikemik Oral) atau kombinasi OHO dengan insulin minimal 1 bulan pemakaian, terlibat dalam penelitian ini. Data diambil dari rekam medik dan kuesioner. Kepatuhan diukur dengan menggunakan kuesioner MARS 5 (Medication Adherence Report Scale 5). Faktor yang berpengaruh terhadap kepatuhan dianalisis menggunakan uji chi-square. Hasil penelitian menunjukkan bahwa responden yang patuh sebanyak 37 orang $(43,5 \%)$. Faktor yang berpengaruh terhadap kepatuhan secara signifikan adalah penghasilan per-bulan ( $\mathrm{p}$-value $=0,018$ dan OR = 2,887), Pengobatan ( $\mathrm{p}$-value $=0,007$ dan OR =3,551), frekuensi minum obat (p-value = 0,006 dan OR = 3,529), dan kadar gula darah ( $\mathrm{p}$-value = 0,006 dan $\mathrm{OR}=3,529)$.
\end{abstract}

Kata Kunci: faktor-faktor yang mempengaruhi kepatuhan, kepatuhan, diabetes mellitus

\begin{abstract}
Diabetes mellitus is a chronic metabolic with high prevalence and it can increase the risk of the complications, if it not handled properly. Medication adherence is one of the determining factor to achive therapeutic outcome. This research aims to determine the affecting factors of adherence in diabetes mellitus type 2 outpatient at RSUD Sukoharjo in 2020. This research type is cross sectional with a purposive sampling technique. A total of 85 patients diabetes mellitus type 2 outpatient at RSUD Sukoharjo with inclusion criteria received OAD therapy (Oral Antidiabetic Drugs) or a combination of OAD with insulin for at least 1 month, recruited in this study. The data was collected from medical records and questionnaires. Adherence was measured by using the MARS 5 questionnaire (Medication Adherence Report Scale 5). Factors contributing to medication adherence was analyzed by using chi-square test. The results showed that 37 respondents $(43.5 \%)$ were obedient. The significant factors of medication adherence are monthly income ( $p$-value $=0.018$ and $O R=2.887)$, Medication $(p-$ value $=0.007$ and $O R=3,551)$, the frequency of treatment ( $p$-value $=0.006$ and $O R=3,529)$ and blood glucose level ( $p$-value $=0.006$ and $O R=3,529)$. Keywords: Factors affecting medication adherence, medication adherence, diabetes mellitus
\end{abstract}

\section{PENDAHULUAN}

Diabetes melitus (DM) merupakan salah satu masalah kesehatan masyarakat yang sangat serius dengan prevalensi yang selalu meningkat setiap tahunnya. Prevalensi kasus diabetes melitus tipe 2 mencapai $90-95 \%$ dari keseluruhan populasi dunia (Mokolomban et al., 2018). Berdasarkan data International Diabetes Federation (IDF), jumlah penderita diabetes melitus di Indonesia pada tahun 2014 telah mencapai 9,1 juta orang dan diperkirakan akan meningkat menjadi 14,1 
juta orang pada tahun 2035. Hal tersebut membuat Indonesia menempati peringkat ke5 sebagai penyandang DM terbesar di dunia (PERKENI, 2015).

Salah satu penyebab kenaikan angka morbiditas dan mortalitas DM di Indonesia adalah ketidakpatuhan pasien terhadap pengobatan. Sebagian besar masalah saat ini adalah penderita diabetes melitus tidak mengerti tentang tujuan terapi yang dilakukan sehingga akan menimbulkan dampak buruk pada penderitanya (Alfian and Putra, 2017). Selain itu, ketidakpatuhan pasien diabetes melitus terhadap pengobatan juga dipengaruhi oleh berbagai faktor diantaranya variabel sosio demografis (usia, jenis kelamin, pendidikan), sosio ekonomi (pekerjaan dan pembayaran pengobatan), karakteristik klinik (komorbid dan durasi sakit) serta obat (frekuensi dan jumlah obat) (Akrom et al., 2019).

Menurut laporan World Health Organization (2003) kepatuhan terapi jangka panjang untuk penyakit kronis di negaranegara berkembang kurang dari $50 \%$ dibandingkan dengan negara maju. Begitupun hasil penelitian yang dilakukan oleh Alfian (2015) di RSUD Dr. H. Moch. Ansari Saleh Banjarmasin pada 110 responden menunjukkan bahwa tingkat kepatuhan pasien masih tergolong rendah yaitu sebanyak 47 pasien $(42,7 \%)$ sedangkan tingkat kepatuhan tinggi hanya 20 pasien $(18,2 \%)$, dan tingkat kepatuhan sedang 43 pasien $(39,1 \%)$. Penelitian serupa yang dilakukan Fatmawati (2017) menunjukkan bahwa pasien diabetes melitus tipe 2 di RSUD Dr. Moewardi Surakarta pada periode Oktober 2016 - Maret 2017 dengan jumlah 98 responden memiliki tingkat kepatuhan yang tergolong rendah yaitu sebanyak 71 orang $(72,45 \%)$ dan kepatuhan tinggi sebanyak 27 orang $(27,55 \%)$. Menurut penelitian Rasdianah et al., (2016) beberapa alasan utama pasien tidak meminum obat dikarenakan aktivitas yang padat $(46,6 \%)$, hal ini terkait dengan subjek penelitian yang sebagian besar masih bekerja dan produktif, alasan lainnya yaitu obat habis $(14,8 \%)$ dan lupa mengkonsumsi obat $(13,6 \%)$.

Kepatuhan pasien untuk minum obat memegang peranan yang sangat penting pada keberhasilan terapi untuk menjaga kadar glukosa darah agar berada dalam rentang normal (Mokolomban et al., 2018). Kepatuhan pengobatan itu sendiri dapat didefinisikan sebagai suatu perilaku pasien untuk melaksanakan terapi atau pengobatan secara teratur, mengikuti pola makan dan diet yang dianjurkan, serta melakukan perubahan gaya hidup sesuai dengan rekomendasi yang disepakati dari penyedia layanan kesehatan (World Health Organization, 2003).

Kepatuhan pengobatan yang rendah tentunya akan berdampak negatif pada peningkatan berbagai macam penyakit komplikasi, peningkatan resiko biaya perawatan, dan resiko terjadinya rawat inap. Komplikasi yang dapat ditimbulkan pada penderita diabetes melitus meliputi komplikasi mikrovaskuler (retinopati, neuropati, dan nefropati) dan komplikasi makrovaskular seperti jantung koroner, stroke, kardiovaskuler dan pembuluh darah (Dipiro et al., 2017). Mengidentifikasi pasien yang tidak patuh dalam pengobatan rawat jalan menjadi sangat penting untuk dilakukan agar dapat melaksanakan terapi yang efektif, mencegah terjadinya komplikasi sehingga dapat meningkatkan kualitas hidup pasien (Srikartika et al., 2016).

Oleh sebab itu, perlu dilakukan penelitian mengenai faktor-faktor yang mempengaruhi kepatuhan minum obat pasien DM tipe 2 di instalasi rawat jalan RSUD Sukoharjo. Hal ini dikarenakan jumlah penderita diabetes melitus di RSUD Sukoharjo pada tahun 2014 telah mencapai 645 kasus dan diperkirakan terus meningkat setiap tahunnya (Dinkes Sukoharjo, 2014). Hasil penelitian ini diharapkan dapat bermanfaat dan dijadikan evaluasi untuk tenaga kesehatan khususnya farmasis dalam hal memberikan pelayanan kesehatan, konseling dan edukasi terhadap pasien sehingga diharapkan dapat meningkatkan kepatuhan minum obat pasien 
dan tercapainya keberhasilan terapi yang diinginkan.

\section{METODE PENELITIAN \\ Desain Penelitian}

Penelitian yang dilakukan merupakan jenis penelitian non-eksperimental dengan pendekatan cross sectional . Data diambil dari rekam medik serta wawancara secara langsung kepada pasien yang terdiagnosis diabetes melitus tipe 2. Penelitian dilakukan di instalasi rawat jalan RSUD Sukoharjo selama dua bulan.

\section{Populasi dan Sampel}

Populasi pada penelitian ini adalah pasien diabetes melitus tipe 2 di instalasi rawat jalan RSUD Sukoharjo tahun 2020. Teknik pengambilan sampel yang digunakan dalam penelitian ini purposive sampling. Populasi yang termasuk kriteria inklusi yaitu pasien rawat jalan RSUD Sukoharjo yang bersedia untuk diwawancara termasuk mengisi kuesioner dan menandatangani informed consent, menderita penyakit DM tipe 2 dengan atau tanpa penyakit penyerta maupun komplikasi, usia pasien $\geq 18$ tahun, pasien mendapatkan terapi $\mathrm{OHO}$ (Obat Hipoglikemik Oral) atau kombinasi OHO dengan insulin minimal 1 bulan, sedangkan populasi yang termasuk kriteria ekslusi yakni pasien tuli dan gangguan jiwa. Dengan keterbatasan waktu peneliti, maka sampel yang dapat diambil pada penelitian ini hanya 85 pasien.

\section{Variabel penelitian}

Variabel bebas yang termasuk dalam penelitian ini adalah usia, jenis kelamin, pekerjaan, pendidikan, penghasilan, asuransi kesehatan, durasi atau lamanya penyakit, frekuensi minum obat, kadar gula darah (GDS atau GDP), IMT, komplikasi, penyakit penyerta, jenis pengobatan dan polifarmasi pada pasien DM tipe 2. Sedangkan variabel tergantungnya adalah kepatuhan pasien diabetes mellitus.

\section{Instrumen penelitian}

Pada penelitian ini menggunakan 2 macam data yakni data primer (wawancara langsung kepada pasien) serta data sekunder (data rekam medik pasien). Data yang diambil dari rekam medik adalah profil pengobatan pasien yang terdiri dari nama, nomor rekam medik, Pengobatan (monoterapi dan kombinasi), polifarmasi (penggunaan obat $\geq 5$ macam obat), frekuensi minum obat, kadar gula darah (GDS atau GDP), komplikasi dan penyakit penyerta. Wawancara kepada pasien untuk mendapatkan data demografi dan kepatuhan. Data demografi pasien meliputi nama, usia, jenis kelamin, berat badan dan tinggi badan, pekerjaan, pendidikan, penghasilan, lama penyakit DM, serta asuransi kesehatan. Kuesioner MARS 5 untuk mengukur kepatuhan, terdiri dari 5 pertanyaan dan diukur menggunakan skala likert dengan rentang nilai dari 1 (selalu) - 5 (tidak pernah). MARS-5 telah tersedia dalam versi bahasa Indonesia dan telah divalidasi dengan nilai Cronbach Alpha 0,80315 oleh Alfian dan Putra (2017). MARS-5 terdiri dari 5 item pertanyaan yang menilai perilaku ketidakpatuhan (lupa, mengubah dosis, berhenti, melewatkan dosis, dan menggunakan obat kurang dari yang diresapkan).

Kuesioner kepatuhan dapat dilihat pada tabel 1. Kategori kepatuhan dibedakan menjadi 2 yaitu patuh (kepatuhan tinggi) apabila jumlah skor dari seluruh pertanyaan yang diperoleh adalah 25 dan tidak patuh (kepatuhan rendah) apabila skor yang diperoleh adalah < 25 (Katadi et al., 2019).

\section{Analisis Data}

Pada penelitian ini digunakan analisis univariat digunakan untuk menganalisa frekuensi dan persentase (\%) masing-masing dari variabel bebas dan variabel terikat. Analisis bivariat yang digunakan dalam penelitian ini adalah analisis statistik nonparametrik dengan uji Chi square karena memiliki distribusi data yang tidak normal. Apabila hasil p-value menunjukkan $<0,05$ maka hasil data tersebut dikatakan signifikan atau terdapat hubungan antara kedua variabel serta menggunakan perhitungan nilai OR (Odd Ratio) untuk mengetahui seberapa besar pengaruh variabel bebas terhadap variabel 
Tabel 1. Karakteristik pasien diabetes melitus tipe 2 di instalasi rawat jalan RSUD Sukoharjo

\begin{tabular}{|c|c|c|c|c|}
\hline & Variabel & Patuh n (\%) & Tidak Patuh n (\%) & Total n (\%) \\
\hline Kepat & an pasien & $37(43,5)$ & $48(56,5)$ & \\
\hline \multicolumn{5}{|c|}{ Usia } \\
\hline- & $<60$ tahun & $20(23,5)$ & $32(37,6)$ & $52(61,2)$ \\
\hline - & $\geq 60$ tahun & $17(20,0)$ & $16(18,8)$ & $33(38,8)$ \\
\hline \multicolumn{5}{|c|}{ Jenis kelamin } \\
\hline- & Perempuan & $23(27,1)$ & $22(25,9)$ & $45(52,9)$ \\
\hline- & Laki - laki & $14(16,5)$ & $26(30,6)$ & $40(47,1)$ \\
\hline \multicolumn{5}{|c|}{ Pendidikan } \\
\hline- & Tinggi & $13(15,3)$ & $12(14,1)$ & $25(29,4)$ \\
\hline- & Rendah & $24(28,2)$ & $36(42,4)$ & $60(70,6)$ \\
\hline \multicolumn{5}{|l|}{ IMT } \\
\hline & $<23 \mathrm{~kg} / \mathrm{m}^{2}$ & $22(25,9)$ & $19(22,4)$ & $41(48,2)$ \\
\hline- & $\geq 23 \mathrm{~kg} / \mathrm{m}^{2}$ & $15(17,6)$ & $29(34,1)$ & $44(51,8)$ \\
\hline \multicolumn{5}{|c|}{ Penghasilan } \\
\hline- & $\geq \mathrm{UMK}$ & $21(24,7)$ & $15(17,6)$ & $36(42,4)$ \\
\hline- & $<\mathrm{UMK}$ & $16(18,8)$ & $33(38,8)$ & $49(57,6)$ \\
\hline \multicolumn{5}{|c|}{ Pekerjaan } \\
\hline- & Tidak bekerja & $21(24,7)$ & $31(36,5)$ & $52(61,2)$ \\
\hline- & Bekerja & $16(18,8)$ & $17(20,0)$ & $33(38.8)$ \\
\hline \multicolumn{5}{|c|}{ Asuransi Kesehatan } \\
\hline- & BPJS & $34(40,0)$ & $47(55,3)$ & $81(95,3)$ \\
\hline- & Umum & $3(3,5)$ & $1(1,2)$ & $4(4,7)$ \\
\hline
\end{tabular}

terikat. Data hasil penelitian dianalisis menggunakan program dari komputer yaitu SPSS 23 (Statistical Product and Service Solutions 23).

\section{HASIL DAN PEMBAHASAN}

Pada penelitian ini jumlah sampel yang memenuhi kriteria inklusi sebanyak 85 pasien. Distribusi karakteristik pasien diabetes melitus tipe 2 di instalasi rawat jalan RSUD Sukoharjo tahun 2020 dapat dilihat pada tabel 1 .

Berdasarkan tabel 1, karakteristik pasien yang meliputi faktor sosio demografi terdiri dari usia, jenis kelamin, pendidikan dan IMT. Usia pasien DM tipe 2 rawat jalan sebagian besar berada pada usia < 60 tahun yaitu sebanyak 52(61,2\%) pasien. Mayoritas penderita berjenis kelamin perempuan sebanyak 45 orang $(52,9 \%)$. Perempuan yang pernah memiliki riwayat melahirkan bayi dengan berat lebih dari $4 \mathrm{~kg}$ dan mempunyai riwayat diabetes melitus gestasional termasuk faktor resiko diabetes mellitus (PERKENI, 2015). Selain itu terjadinya diabetes mellitus pada perempuan juga bias disebabkan karena penurunan hormon estrogen akibat dari sindrom siklus bulanan (premenstrual syndrome) dan pasca-menopouse yang membuat distribusi lemak tubuh menjadi mudah terakumulasi (Idris et al., 2017). Sebanyak $60(70,6 \%)$ pasien memiliki tingkat pendidikan yang rendah (tidak sekolah, SD, SMP, SMA). Nilai IMT pasien $\geq 23 \mathrm{~kg} / \mathrm{m}^{2}$ (berat badan berlebih dan obesitas) sebanyak 44 orang $(51,8 \%)$.

Karakteristik pasien yang meliputi faktor ekonomi terdiri dari penghasilan, pekerjaan dan asuransi kesehatan yang digunakan. Berdasarkan hasil penelitian, responden sebagian besar memiliki penghasilan dibawah UMK yaitu sebanyak 49 orang $(57,6 \%)$. Pasien DM tipe 2 rawat jalan mayoritas sudah tidak bekerja sebanyak 52 orang $(61,2 \%)$. Dalam penelitian ini tidak selalu pasien yang tidak bekerja memiliki penghasilan yang rendah, terutama pada pensiunan PNS yang umumnya mendapatkan tunjangan pensiun setiap bulannya. Selain itu, hampir seluruh responden sudah menggunakan asuransi kesehatan BPJS sejumlah 81 orang dengan persentase sebesar $95,3 \%$.

Karakteristik faktor klinis pasien terdiri dari durasi sakit, komplikasi, penyakit 
Tabel 2. Karakteristik klinis dan obat pasien diabetes melitus tipe 2 di instalasi rawat jalan RSUD Sukoharjo

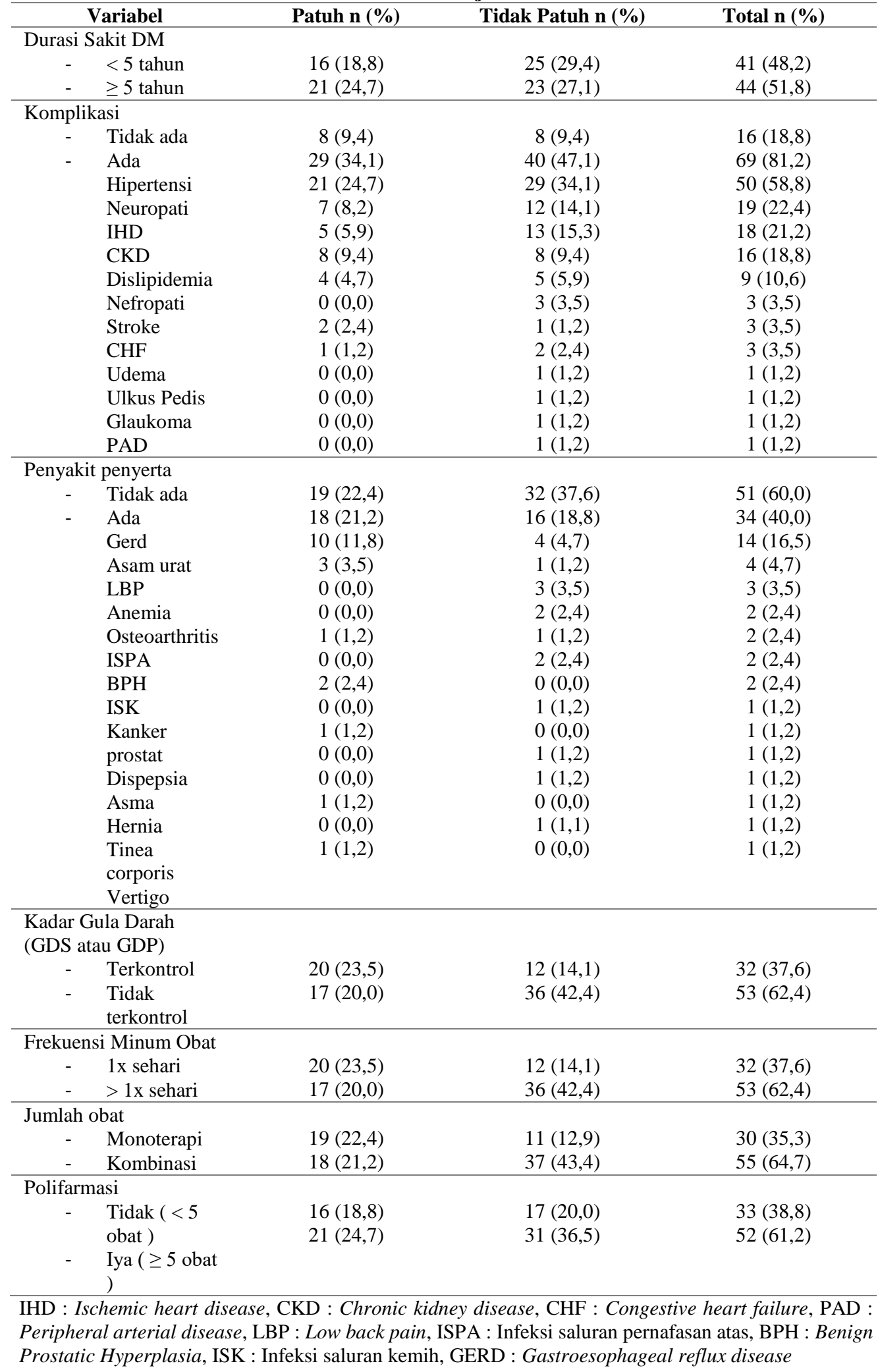

penyerta dan kadar gula darah responden (GDS atau GDP) (Tabel 2). Mayoritas pasien
DM, 44 orang $(51,8 \%)$, pada penelitian ini memiliki durasi sakit lebih dari 5 tahun. Pasien 
DM tipe 2 yang memiliki komplikasi berjumlah 69 orang $(81,2 \%)$, komplikasi yang paling banyak terjadi pada pasien DM tipe 2 rawat jalan di RSUD Sukoharjo yaitu hipertensi $(58,8 \%)$. Selain adanya komplikasi, pasien juga memiliki penyakit penyerta, terdapat 51 orang $(60,0 \%)$ pasien yang memiliki penyakit penyerta. Sebagian besar responden memiliki kadar gula darah yang tidak terkontrol sejumlah 53 orang $(62,4 \%)$, hal ini dikarenakan hasil terapi pasien memiliki kadar GDS $\geq 200 \mathrm{mg} / \mathrm{dl}$ atau GDP $\geq$ $126 \mathrm{mg} / \mathrm{dl}$.

Karakteristik pasien yang meliputi faktor obat terdiri dari frekuensi minum obat, jenis pengobatan yang digunakan serta polifarmasi Tabel 2). Mayoritas pasien memiliki frekuensi minum obat lebih dari sekali sehari yaitu sejumlah 53 orang $(62,4 \%)$. Pasien DM tipe 2 lebih banyak mengonsumsi obat antidiabetes kombinasi daripada obat monoterapi yaitu sebanyak 55 orang dengan persentase sebesar $64,7 \%$. Selain itu, perbandingan pasien yang mengonsumsi obat polifarmasi $(\geq 5$ macam obat) jauh lebih besar $(61,2 \%)$ dibandingkan yang tanpa menggunakan obat polifarmasi $(38,8 \%)$.

Hasil penelitian karakteristik tingkat kepatuhan minum obat pasien DM tipe 2 rawat jalan di RSUD Sukoharjo tahun 2020 dengan menggunakan 85 sampel penelitian dapat dilihat pada tabel 3. Tingkat kepatuhan minum obat tersebut diukur menggunakan instrumen MARS 5 dengan kategori patuh dan tidak patuh. Sebagian besar pasien DM tipe 2 berada pada kategori tidak patuh minum obat dengan jumlah sebanyak 48 orang $(56,5 \%)$, sedangkan pasien yang patuh minum obat yaitu 37 orang $(43,5 \%)$.

Berdasarkan tabel 3, yang berpengaruh terhadap kepatuhan minum obat adalah penghasilan, frekuensi minum obat, jumlah obat yang diminum dan kadar gula darah (nilai $\mathrm{p}<0,05)$. Beberapa faktor yang bisa mempengaruhi kepatuhan seperti lamanya penyakit, IMT, dan adanya komplikasi tidak terbukti pada penelitian ini. Hal ini bisa disebabkan karena sampel penelitian yang memang hanya sedikit. Hasil penelitian ini sejalan dengan penelitian yang dilakukan oleh (Julaiha, 2019) menunjukkan terdapat hubungan yang signifikan antara pendapatan dengan kepatuhan berobat ( $\mathrm{p}$-value $=0,000$ ). Pendapatan pasien berkaitan erat dengan status kesehatan, umumnya semakin tinggi pendapatan maka akan semakin baik status kesehatannya (Aini et al., 2011). Begitupun penelitian yang dilakukan oleh Hakim (2018), menyatakan bahwa semakin tinggi penghasilan maka akan meningkatkan kesadaran responden untuk berobat sehingga komplikasi kronis DM tipe 2 dapat dicegah, pendapatan juga berkaitan dengan kemampuan diri dalam melakukan pemeriksaan, penyediaan makanan sesuai diet diabetes dan pengobatan. Pendapatan yang rendah tentunya akan memberikan dampak negatif terhadap kepatuhan pengobatan, hal ini dikarenakan pasien sering kali mengalami kendala terkait keuangan yang ditanggungnya seperti biaya obat yang mahal dan biaya transportasi yang harus dikeluarkan untuk menuju ke sarana kesehatan. (Bagonza et al., 2015).

Penelitian ini menunjukkan bahwa tidak ada hubungan yang signifikan antara komplikasi dengan kepatuhan minum obat pasien DM tipe 2 rawat jalan di RSUD Sukoharjo. Penelitian ini sejalan dengan Srikartika et al. (2016) yang menyatakan bahwa komplikasi tidak berpengaruh terhadap kepatuhan penggunaan obat ( $\mathrm{p}$-value $=0,147)$. Pada penelitian ini pasien yang memiliki komplikasi cenderung tidak patuh minum obat yaitu sebesar 40 orang $(47,1 \%)$. Banyaknya pasien yang menderita komplikasi ini dikarenakan mayoritas sudah lama menderita DM tipe 2, sebagaimana yang diungkapkan oleh Katadi et al. (2019) semakin lama seseorang menderita DM maka risiko untuk terjadinya komplikasi akan semakin besar. Menurut Almira et al. (2019) pasien yang memiliki komplikasi akan mengkonsumsi obat dalam jumlah lebih banyak dan kompleks sehingga dapat menurunkan tingkat kepatuhan pasien dalam minum obat. DM tipe 2 juga 
Tabel 3. Hubungan karakteristik pasien dengan kepatuhan minum obat pasien diabetes melitus tipe 2 di instalasi rawat jalan RSUD Sukoharjo

\begin{tabular}{|c|c|c|c|c|c|c|c|c|}
\hline \multicolumn{2}{|r|}{ Variabel } & \multicolumn{2}{|c|}{ Patuh } & \multicolumn{2}{|c|}{ Tidak Patuh } & \multirow[t]{2}{*}{$\mathrm{P}$ - value } & \multirow[t]{2}{*}{ OR } & \multirow[t]{2}{*}{$95 \% \mathrm{Cl}$} \\
\hline & & $\mathrm{N}$ & $\%$ & $\mathrm{n}$ & $\%$ & & & \\
\hline \multicolumn{9}{|l|}{ Usia } \\
\hline- & $<60$ tahun & 20 & 23,5 & 32 & 37,6 & 0,237 & 0,588 & $0,243-1,421$ \\
\hline- & $\geq 60$ tahun & 17 & 20,0 & 16 & 18,8 & & & \\
\hline \multicolumn{9}{|c|}{ Jenis Kelamin } \\
\hline- & Perempuan & 23 & 27,1 & 22 & 25,9 & 0,135 & 1,942 & $0,810-4,653$ \\
\hline- & Laki - laki & 14 & 16,5 & 26 & 30,6 & & & \\
\hline \multicolumn{9}{|c|}{ Pendidikan } \\
\hline- & Tinggi ( > 12 tahun) & 13 & 15,3 & 12 & 14,1 & 0,309 & 1,625 & $0,635-4,157$ \\
\hline- & Rendah ( $\leq 12$ tahun) & 24 & 28,2 & 36 & 42,4 & & & \\
\hline \multicolumn{9}{|c|}{ - } \\
\hline- & $<23 \mathrm{~kg} / \mathrm{m}^{2}$ & 22 & 25,9 & 19 & 22,4 & 0,069 & 2,239 & $0,933-5,369$ \\
\hline - & $\geq 23 \mathrm{~kg} / \mathrm{m}^{2}$ & 15 & 17,6 & 22 & 34,1 & & & \\
\hline \multicolumn{9}{|c|}{ Penghasilan } \\
\hline- & $\geq \mathrm{UMK}$ & 21 & 24,7 & 15 & 17,6 & $0,018 *$ & 2,887 & $1,183-7,045$ \\
\hline- & $<\mathrm{UMK}$ & 16 & 18,8 & 33 & 38,8 & & & \\
\hline \multicolumn{9}{|c|}{ Pekerjaan } \\
\hline- & Tidak Bekerja & 21 & 24,7 & 31 & 36,5 & 0,463 & 0,720 & $0,299-1,734$ \\
\hline- & Bekerja & 16 & 18,8 & 17 & 20,0 & & & \\
\hline \multicolumn{9}{|c|}{ Asuransi Kesehatan } \\
\hline- & BPJS & 34 & 40,0 & 47 & 55,3 & 0,193 & 0,241 & $0,024-2,419$ \\
\hline- & UMUM & 3 & 3,5 & 1 & 1,2 & & & \\
\hline \multicolumn{9}{|c|}{ Durasi sakit DM } \\
\hline- & $<5$ tahun & 16 & 18,8 & 25 & 29,4 & 0419 & 0701 & 0 296-1 660 \\
\hline- & $\geq 5$ tahun & 21 & 24,7 & 23 & 27,1 & 0,419 & $0, / 01$ & $0,290-1,000$ \\
\hline \multicolumn{9}{|c|}{ Komplikasi } \\
\hline- & Tidak ada & 8 & 9,4 & 8 & 9,4 & & & \\
\hline- & Ada & 29 & 34,1 & 40 & 47,1 & 0,502 & $1,3 / 9$ & $0,464-4,104$ \\
\hline \multicolumn{9}{|c|}{ Penyakit Penyerta } \\
\hline- & Tidak ada & 19 & 22,4 & 32 & 37,6 & 0153 & 0528 & (2) 219-1273 \\
\hline- & Ada & 18 & 21,2 & 16 & 18,8 & 0,153 & $0,5<0$ & $0,219-1,2 / 3$ \\
\hline \multicolumn{9}{|c|}{ Kadar Gula Darah (GDS atau } \\
\hline GDP) & & 20 & 23,5 & 12 & 14,1 & & & \\
\hline- & Terkontrol & 17 & 20,0 & 36 & 42,4 & $0,006^{*}$ & 3,529 & $1,408-8,849$ \\
\hline- & Tidak Terkontrol & & & & & & & \\
\hline \multicolumn{9}{|c|}{ Frekuensi Minum Obat } \\
\hline- & 1x sehari & 20 & 23,5 & 12 & 14,1 & $0006 *$ & 3529 & $1408-8849$ \\
\hline- & $>1 x$ sehari & 17 & 20,0 & 36 & 42,4 & & & \\
\hline \multicolumn{9}{|c|}{ Pengobatan } \\
\hline- & Monoterapi & 19 & 22,4 & 11 & 12,9 & & 3551 & \\
\hline- & Kombinasi & 18 & 21,2 & 37 & 43,5 & $0,00 / *$ & 3,551 & $1,398-9,017$ \\
\hline \multicolumn{9}{|c|}{ Polifarmasi } \\
\hline- & Tidak (<5 obat) & 16 & 18,8 & 17 & 20,0 & 0.463 & 1389 & $0577-3,347$ \\
\hline- & Iya ( $\geq 5$ obat $)$ & 21 & 24,7 & 31 & 36,5 & 0,403 & & ו \\
\hline
\end{tabular}

IMT : Indeks massa tubuh, UMK : Upah minimum kerja, OR : Odds ratio

*Signifikan p-value < 0,05

(-)Tidak dilakukan analisis bivariat

sama seperti penyakit kronis lainnya, dapat mengakibatkan timbulnya penyakit lain apabila kadar glukosa darah tidak terkontrol.

Pada penelitian ini, terdapat hubungan antara kepatuhan menggunakan obat dengan kadar gula darah $(\mathrm{p}$-value $=0,006)$. Hasil penelitian ini selaras dengan penelitian yang dilakukan oleh Nandini et al., (2020) bahwa faktor yang mempengaruhi kepatuhan adalah kadar gula darah yang terkontrol ( $\mathrm{p}$-value $=$ $0,007)$. 
Frekuensi minum obat merupakan salah satu faktor yang dapat mempengaruhi kepatuhan minum obat pasien. Berdasarkan tabel 3, diketahui bahwa nilai p-value $=0,006$ dan $\mathrm{OR}=3,529(95 \% \mathrm{Cl} 1,408-8,849)$ hal ini menunjukkan terdapat hubungan yang signifikan antara frekuensi minum obat dengan kepatuhan minum obat pasien DM tipe 2 rawat jalan di RSUD Sukoharjo. Nilai OR = 3,529 memiliki arti bermakna bahwa pasien dengan frekuensi minum obat sekali sehari memiliki kecenderungan untuk patuh minum obat sebesar 3,529 kali. Dalam penelitian Akrom et al. (2019) menyatakan juga bahwa frekuensi pengobatan berhubungan signifikan terhadap kepatuhan minum obat ( $\mathrm{p}$-value $=$ 0,040). Pasien yang mendapat obat antidiabetes dengan frekuensi minum obat sekali sehari cenderung lebih patuh dibandingkan frekuensi minum obat dua kali sehari atau lebih. Namun hal ini tentunya berkaitan juga dengan kesadaran pasien untuk patuh berobat sesuai anjuran dokter dan tenaga kesehatan lainnya, berapapun jumlah dan regimen pengobatan yang diberikan tanpa adanya kesadaran pasien untuk patuh maka hasil terapi pun tidak akan optimal dan akan berefek terjadinya kegagalan terapi (Adikusuma and Qiyaam, 2017).

Hasil penelitian ini menunjukkan bahwa terdapat hubungan yang signifikan antara pengobatan dengan kepatuhan minum obat pasien DM tipe 2 rawat jalan di RSUD Sukoharjo ( $\mathrm{p}$-value $=0,007)$. Persentase pasien yang mengkonsumsi obat antidiabetik monoterapi lebih patuh $(22,4 \%)$ dibandingkan yang mengkonsumsi obat antidiabetik kombinasi $(21,2 \%)$, dan sebaliknya pasien yang menerima obat kombinasi cenderung tidak patuh $(43,5 \%)$ dibandingkan yang menerima obat antidiabetik monoterapi $(12,9 \%)$. Hasil serupa ditunjukkan oleh penelitian Fatmawati (2017) yang menunjukkan bahwa jumlah obat berpengaruh terhadap kepatuhan minum obat pada pasien DM dengan perolehan $\mathrm{p}$-value $=0,049$.

Penelitian ini memiliki keterbatasan saat pengambilan data yakni sampel dengan jumlah yang sedikit sehingga kemungkinan dapat mempengaruhi hasil penelitian. Selain itu, peneliti juga tidak melakukan pengukuran tinggi badan pada pasien yang mengalami kelumpuhan sehingga data yang didapat hanya bersumber dari keterangan pasien. Faktor yang tidak dapat dimodifikasi pada penelitian ini yaitu penghasilan, sedangkan faktor yang dapat dimodifikasi adalah pengobatan, dan frekuensi minum obat antidiabetik. Untuk itu peran serta apoteker diperlukan untuk meninjau ulang terkait obat kombinasi antidiabetik dengan memberikan rejimen pengobatan yang lebih sederhana untuk memudahkan pasien minum obat seperti memberikan sediaan obat kombinasi satu tablet dengan dua zat aktif obat antidiabetes dan melakukan edukasi kepada pasien untuk memodifikasi gaya hidup sehat sehingga diharapkan kadar glukosa darah pasien tetap terkontrol.

\section{KESIMPULAN}

Berdasarkan hasil penelitian ini terdapat $37(43,5 \%)$ pasien yang patuh terhadap pengobatan diabetes mellitus. Penghasilan, jumlah obat DM, frekuensi pengobatan, dan kadar gula darah berpengaruh secara signifikan terhadap kepatuhan minum obat.

\section{Daftar Pustaka}

Adikusuma W. and Qiyaam N., 2017, Hubungan Tingkat Kepatuhan Minum Obat Antidiabetik Oral Terhadap Kadar Hemoglobin Terglikasi (HbA1c) pada Pasien Diabetes Melitus Tipe 2, Jurnal Ilmiah Ibnu Sina, 2 (2), 279-286.

Ahmad N.S., Ramli A., Islahudin F. and Paraidathathu T., 2013, Medication Adherence in Patients with Type 2 Diabetes Mellitus Treated at Primary Health Clinics in Malaysia, 
Patient Preference and Adherence, 7, 525-530.

Aini N., Fatmaningrum W. and Yusuf A., 2011, Peningkatkan Perilaku Pasien dalam Tatalaksana Diabetes Melitus Menggunakan Model Behavioral System, Jurnal Ners, 6 (1), 1-10.

Ainni A.N., 2017, Studi Kepatuhan Penggunaan Obat Pada Pasien Diabetes Melitus Tipe 2 di Instalasi Rawat Jalan RSUD Dr. Tjitrowardojo Purworejo Tahun 2017, Skripsi, Fakultas Farmasi, Universitas Muhammadiyah Surakarta.

Akrom, Sari O.M., Urbayatun S. and Saputri Z., 2019, Analisis Determinan Faktor-Faktor yang Berhubungan dengan Kepatuhan Minum Obat Pasien Diabetes Tipe 2 Di Pelayanan Kesehatan Primer, Jurnal Sains Farmasi \& Klinis, 6 (1), 54-62.

Alfian R., 2015, Korelasi Antara Kepatuhan Minum Obat dengan Kadar Gula Darah pada Pasien Diabetes Melitus Rawat Jalan di RSUD Dr. H. Moch. Ansari Saleh Banjarmasin, Jurnal Pharmascience, 2 (2), 15-23.

Alfian R. and Putra A.M.P., 2017, Uji Validitas dan Reliabilitas Kuesioner Medication Adherence Report Scale (MARS) Terhadap Pasien Diabetes Mellitus, Jurnal Ilmiah Ibnu Sina, 2 (2), 176-183.

Almira N., Syamsul A. and Rosida L., 2019, Faktor - Faktor yang Berhubungan dengan Perilaku Kepatuhan Minum Obat Anti Diabetes pada Penderita Diabetes Melitus Tipe 2 di Puskesmas Teluk Dalam Banjarmasin, Homeostasis, 2 (1), 1-12.

American Diabetes Association, 2018, Standards of Medical Care in Diabetes, Diabetes Care, $41(1), 11-16$.

Anggraini T.D. and Puspasari N., 2019, Tingkat Kepatuhan Penggunaan Obat Antidiabetik Pada Pasien Diabetes Melitus Tipe 2 Di Apotek Sehat Kabupaten Boyolali, Indonesian Journal On Medical Science, 6 (2), 1-8.

Bagonza J., Rutebemberwa E. and Bazeyo W., 2015, Adherence to Anti Diabetic Medication Among Patients with Diabetes in Eastern Uganda; A Cross Sectional Study, BMC Health Services Research, 15 (1), 1-7.

Dipiro J.T., Talbert R.L., Yee G.C., Matzke G.R., Wells B.G. and Posey L.M., 2017, Pharmacotherapy A Pathophysiologic Approach, 10th ed., McGraw-Hill Education Companies, Inggris.

Elsous A., Radwan M., Al-Sharif H. and Mustafa A.A., 2017, Medications Adherence and Associated Factors among Patients with Type 2 Diabetes Mellitus in the Gaza Strip, Palestine, Frontiers in Endocrinology, 8 (JUN), 1-9.

Fatmawati S.A., 2017, Faktor - Faktor yang Berpengaruh terhadap Kepatuhan Minum Obat Pasien Diabetes Mellitus Tipe 2 di RSUD Dr. Moewardi Periode Oktober 2016 - Maret 2017, Skripsi, Fakultas Farmasi, Universitas Muhammadiyah Surakarta.

Hakim D.L., 2018, Hubungan Tingkat Sosial Ekonomi : Pendidikan, Penghasilan, dan Fasilitas 
dengan Pencegahan Komplikasi Kronis pada Penyandang Diabetes Melitus Tipe 2, Skripsi, Fakultas Farmasi, Universitas Muhammadiyah Surakarta.

Handayani I.B., 2012, Evaluasi Tingkat Kepatuhan Penggunaan Obat pada Pasien Diabetes Mellitus Tipe 2 di Instalasi Rawat Jalan RSUD Kabupaten Sukoharjo, Skripsi, Fakultas Farmasi, Universitas Muhammadiyah Surakarta.

Jin H.K., Kim Y.H. and Rhie S.J., 2016, Factors Affecting Medication Adherence in Elderly People, Patient Preference and Adherence, 10, 2117-2125.

Julaiha S., 2019, Analisis Faktor Kepatuhan Berobat Berdasarkan Skor MMAS-8 pada Pasien Diabetes Mellitus Tipe 2, Jurnal Kesehatan, 10 (2), 203.

Katadi S., Andayani T.M. and Endarti D., 2019, Hubungan Kepatuhan Pengobatan dengan Outcome Klinik dan Kualitas Hidup Pasien Diabetes Melitus Tipe 2, Jurnal Manajemen dan Pelayanan Farmasi, 9 (1), 19-26.

KEMENKES R., 2018, Hasil Utama Riset Kesehatan Dasar (RISKESDAS), Journal of Physics A: Mathematical and Theoretical, 44 (8), 1-200. Terdapat di: https://www.kemkes.go.id /resources/download/info-terkini/hasil-riskesdas-2018.pdf [Diakses pada April 11, 2020].

KEMENKES R., 2016, Penyelenggaraan Pelayanan Kesehatan Geriatri di Rumah Sakit: Peraturan Menteri Kesehatan Republik Indonesia Nomor 79 Tahun 2014, Kementerian Kesehatan Republik Indonesia, Jakarta. Terdapat di: http://www.kesga.kemkes.go.id/images/ pedoman/Permenkes No. 79 Tahun 2014 Yankes Geriatri RS Tahun 2014.pdf [Diakses pada May 1, 2020].

König H.H., Heider D., Lehnert T., Riedel-Heller S.G., Angermeyer M.C., Matschinger H., Vilagut G., Bruffaerts R., Haro J.M., de Girolamo G., de Graaf R., Kovess V. and Alonso J., 2010, Health Status of the Advanced Elderly in Six European Countries: Results from a Representative Survey using EQ-5D and SF-12, Health and Quality of Life Outcomes, 8 (143), 1-11.

Lathifah N.L., 2017, Hubungan Durasi Penyakit dan Kadar Gula Darah dengan Keluhan Subyektif Penderita Diabetes Melitus, Jurnal Berkala Epidemiologi, 5 (2), 231-239.

Lenny and Fridalina, 2018, Faktor-Faktor yang Berhubungan dengan Kepatuhan Berobat Jalan Pasien Diabetes Mellitus Tipe II, Jurnal Ilmu Kesehatan Masyarakat, 7 (2), 85-93.

Mirahmadizadeh A., Khorshidsavar H., Seif M. and Sharifi M.H., 2020, Adherence to Medication, Diet and Physical Activity and the Associated Factors Amongst Patients with Type 2 Diabetes, Diabetes Therapy, 11 (2), 479-494. Terdapat di: https://doi.org/10.1007/s13300-019-00750-8.

Mokolomban C., Wiyono W.I. and Mpila D.A., 2018, Kepatuhan Minum Obat Pada Pasien Diabetes Melitus Tipe 2 Disertai Hipertensi Dengan Menggunakan Metode MMAS-8, Pharmacon, 7 (4), 69-78.

Nandini H.C., Gali A., Muraraiah S., 2020, Assessment of Factors Influencing Adherence to Antidiabetic Drugs Among Patients with Type 2 Diabetes Mellitus at a Tertiary Care 
Hospital in India, Pharmacology and Clinical Pharmacy Research, 5 (1), 7-13..

PERKENI, 2015, Konsensus Pengelolaan dan Pencegahan Diabetes Melitus Tipe 2 di Indonesia, PERKENI, Jakarta.

Pradana I.P.A., 2015, Hubungan Karakterisktik Pasien dengan Tingkat Kepatuhan dalam Menjalani Terapi Diabetes Melitus di Puskesmas Tembuku 1 Kabupaten Bangli Bali 2015, ISM, 8 (1), 1-5.

Priyono, 2016, Metode Penelitian Kuantitatif, Chandra, T., ed., Zifatama Publishing, Surabaya.

Rasdianah N., Martodiharjo S., Andayani T.M. and Hakim L., 2016, Gambaran Kepatuhan Pengobatan Pasien Diabetes Melitus Tipe 2 di Puskesmas Daerah Istimewa Yogyakarta, Jurnal Farmasi Klinik Indonesia, 5 (4), 249-257.

Siyoto S. and Sodik A.M., 2015, Dasar Metodologi Penelitian, Literasi Media Publishing, Yogyakarta.

Srikartika V.M., Cahya A.D. and Hardiati R.S.W., 2016, Analisis Faktor yang Memengaruhi Kepatuhan Penggunaan Obat Pasien Diabetes Melitus Tipe 2, Jurnal Manajemen dan Pelayanan Farmasi, 6 (3), 205-212.

WHO, 2003, Adherence To Long-Term Therapies, WHO Library Cataloguing, Switzerland.

Willer A.K., Harreiter J. and Pacini G., 2016, Sex and Gender Differences in Risk, Pathophysiology and Complications of Type 2 Diabetes Mellitus, Endocrine Reviews, 37 (3), 278-316. 